\title{
The Analysis of Fixed Work Posts and Defining Personnel Quota of Impermanent Staff from the Perspective of Double-First Class Construction
}

\author{
Yao Chen* \\ School of Humanities and Social Sciences \\ North China Electric Power University \\ Beijing, China \\ 1120869327@qq.com
}

\author{
Guang Liu \\ Logistics Management Office \\ North China Electric Power University \\ Beijing, China \\ 378247@qq.com
}

\begin{abstract}
First-class colleges and universities demand firstclass logistical support. The development of the reform of logistic socialization in colleges and universities witnesses the growth of number of impermanent logistic staffs. Therefore, the efficient management of impermanent staff, which is directly related to the service quality and efficiency of the logistics service, should be strengthened. At the same time, to optimize the allocation of logistics human resources, improve the institutional system, optimize the structure, develop potential, and improve work efficiency through the way of fixed work posts and defining personnel quota to cope with the problem of management and personnel allocation are also needed. Moreover, for the smooth implementation of the fixed work posts and defining personnel quota, it is necessary to promote the orderly development of university logistics under the guidance of relevant scientific and reasonable principles.
\end{abstract}

Keywords-University Logistics; Impermanent Staff; Fixed work posts; Defining Personnel Quot

\section{INTRODUCTION}

In October 2015, the state council issued a formal notice named Push Forward the World First-class University and the First-class Discipline Construction Overall Plan. In view of university construction and discipline construction, the state council has clearly put forward the task requirements of "Double - First". The first class university is a comprehensive evaluation index. During the 13th five-year period, colleges and universities have put the "Double First" construction into the development plan. When he talks about the concept of "First-class University", professor Neil L Rudenstine, President of Harvard University, gives an overview of four "first-rate universities" in this way - first-rate facilities, firstrate faculty, first-rate students and first-rate evaluation [1]. The facilities and evaluation of the four "First Class" are all related to logistics, therefore, logistics is not only the basis and guarantee of the construction of "Double Top" basis, but also an important part of the construction of "Double-Class" universities.
The reform of socialization has gradually developed a new system of personnel system, which could conform to the law of school running and adapt to the socialist market economy. With the implementation of enterprise-style management and the increase of impermanent staff, it solves the bottleneck problem of university logistics human resource management, and improves the management level and service quality. However, in the face of the rapid development of education, most of the logistics staff in colleges and universities are unable to adapt to the needs of "Double-Top" construction. Thereby, how to optimize the management of logistics team in colleges and universities has become an important topic in front of higher education managers [2].

\section{MANAGEMENT STATUS OF LOGISTIC IMPERMANENT STAFF IN COLLEGES AND UNIVERSITIES}

\section{A. Problems in the Management of Senior Management and the Institutional Improvement}

In order to form a system of multi-department joint management, the rules and regulations of staff management need to be jointly formulated by the personnel department, the organization department, the trade union, the security department and the relevant departments of logistics. However, the management system is mainly made by the logistics department itself, so there is no systematic and perfect system because of the inevitably temporality and one-sidedness.

(1) There is no effective system to restrain the post setting and the arrangement of authorized strength. There is no clear standard to follow, no scientific post evaluation and post analysis for checking up the work and authorized strength. The labor standards, such as workload accounting, labor intensity, technical difficulty and operational risk, are selfformulated, which will cause certain blindness and randomness. Not only the specific duties of the post are not clearly defined and the workload is not quantified, but also the posts are forced to be separated. In addition, the phenomenon of setting position by employee and forcing down the authorized strength. 
(2) Employees have limited development space because of lack of systematic and targeted personnel training system. The rational mechanism of talent development has not yet formed, thus the personnel quality is difficult to be promoted in the work. Employees cannot keep abreast of the times and meet new demands. At the same time, it is difficult for employees to achieve a sense of accomplishment, satisfaction and enthusiasm in their work due to the same kind of repetitive work.

(3) The salary system is too simple, so the personnel loss is serious. A reasonable salary system needs reasonable assessment of staff positions and internal and external equilibrium analysis of employee compensation in order to design a reasonable salary structure and determine the scope of compensation, grade. Finally, Colleges and universities could make timely adjustment measures for salary. However, the current salary setting process for impermanent staff is simple, which results in the salary of them is low. Their salary is much lower than that of the staff in the other social sector, so there is no minimum material guarantee.

(4) At present, colleges and universities lack effective incentive mechanism and restraint mechanism so that it is difficult to create a benign competitive atmosphere. There are two modes of enterprise management and administrative management in university logistics department, but they mainly imitates the enterprise operation mode. Therefore, it is inevitable to have congenital defects in the incentive mechanism. Since there is no systematic incentive policy and performance evaluation policy, thus it is difficult to realize the same salary for the same position.

\section{B. The Personnel Structure is not Reasonable and the Manpower Echelon Cannot be Established}

(1) Poor stability of the base team. The logistics of colleges and universities have the problem of poor stability of the base team. Logistics grassroots employees mainly engaged in the frontline jobs, such as maintenance, cleaning, greening, dining room, they do a lot of service security work of "dirty, bitter, tired" , but salary level of them is lower than the social level in the same industry. At the same time, with the rising cost of living in the big cities, the impermanent staff can't get the minimum material guarantee. Therefore, the staff mobility and external staff' $s$ recruitment difficulties have become difficult problems.

(2) The upper echelons rarely transfer jobs, so it's hard for new employees to get promoted. There are still planned economy problems in the logistics of universities, because most of the management positions are engaged by permanent staff so that it is difficult for external employees to enter. In addition, compared to the jobs in teaching and scientific research, the logistics positions, relatively considered as "low" and "weak" work, are in subordinate positions. If there is no school policy support and good development prospects, school staff or social workers are reluctant to enter the logistics service. It is not only difficult to stand out among the outstanding talents in the school, but there is no attractive condition to attract social talents, which ultimately leads to the slow updating of management talents.
(3) Some logistics backbone personnel have low comprehensive quality. This mainly shows that the overall quality of the management team needs to be improved and the talent distribution is unbalanced. Because of quite a number of management personnel without system training, the overall average education level of logistics management personnel is significantly lower than the staff of other management department, so the management experience and management methods are not systematic and scientific. And only a few people with a high degree or senior title are assigned to the department and the administrative department of the central government. They are not engaged in front-line work, so the work efficiency and quality are not guaranteed. .

\section{ANALYZE THE MANageMENT PROBLEMS OF UNIVERSITY LOGISTICS BY THE MEAN OF FIXED WORK POSTS AND DEFInING PERSONNEL QUOTA}

Like college teaching and research, high quality logistics management is an important part of the construction of firstclass universities. The logistics department should first improve the system level, take fixed work posts and defining personnel quota as the main line, and then provide effective incentives as the guarantee, "Different effective management methods are implemented for different management groups." [3] Finally, their talent will be fully unleashed.

\section{A. System Advance: Fixing Work Posts and Defining Personnel Quota and Salary System Reform Supplement Each Other}

The implementation of fixing work posts and defining personnel quota must be coordinated with the reform of the salary system. Reduce identity differences so as to follow the principle of equal pay for equal work. In accordance with the guiding ideology of "Volume Control and Structural Improvement", implement the work of fixing work posts and define personnel quota step by step. While taping the potentialities and increasing the profit, it is necessary to establish a scientific and reasonable wage system for temporary employees, refining the existing salary grades. According to the personnel qualifications, education, seniority and annual assessment results, the salary gap should be widen appropriately and the pay of temporary employees should be raised. In this era, "Internet plus" and big data have been rapidly popularized, and people' $\mathrm{s}$ work, life and thinking will meet with great transformation. Therefore, it must develop a set of human resources management system, which is transformed from traditional, backward, and manual statistical methods to systematized, networked and intelligent management, so as to improve the work efficiency and avoid the interference of human factors. Through the institutionalization of fixing work posts and defining personnel quota and the wage system, it should not only achieve a reasonable match among "talents, posts, and events" , but also attract talents by treatments at the same time. And then efficient logistics entity could be established. 


\section{B. The Shifts of the Working Focus: All Employees Compete for a Job, and Rights, Responsibilities and Benefits are Unified}

At the group level, only general rules shall be formulated, and the implementation of specific rules is handed over to each department to implement in accordance with the actual work of the department. First of all, the logistics departments should in accordance with their work functions, re-organize their business processes, service processes and management processes, set up positions, clarify job responsibilities, write job descriptions, put forward methods of fixing work posts and defining personnel quota and then submit it to the logistics group level for audit. The Group and all departments conduct consultations and discussions based on the principle of "San Shang San Xia" (a program has been negotiated and discussed three times between superiors and subordinates), and carry out job evaluations and job assignments at the same time, clarifying department management sequence, number of posts, and post coefficient etc., clarifying the rights, responsibilities, and benefits and then do the preparatory work for staff appointments. After that, the appointment of the post can be conducted in the form of two-way selection and competition based on the status of the implementation of fixing work posts and defining personnel quota and position requirements. Through the appointment of personnel, a reasonable proportion relationship and a reasonable hierarchy of all types of personnel are achieved, so that the composition of the employees' groups can be optimized to maximize their effectiveness.

\section{Effective Incentive: Appointing People by Their Ability and Making Great Effort to Construct a High Quality Faculty by Using the Strategy of Introduction as well as Development}

Effective incentives will stimulate the vitality of employees and make their work more active, more positive, and more responsible. For employees, by linking rewards and penalties with work performance, not only can a healthy competition atmosphere be created among employees but also the individual values of employees can be organically combined with the unit's goals [4], so as to achieve the effect of rewarding advanced spurs, and ensured that the implementation of fixing work posts and defining personnel quota will be implemented in a virtuous circle. In practice, in addition to the comprehensive use of spiritual incentives and material rewards of different forms, it is more important to work hard to unlock the promotion ways of temporary employees. By using existing policies, employees who want to do things, who can do things, and who can do things successfully can all have their own career development plans, enhance their sense of belonging and sense of achievement, retaining talents through undertaking and remuneration.

For much-needed positions, choosing graduates to strengthen management and technical team or attract talents and technical management team through personnel agency. By applying preferential policy to the school, it could create a good working environment and attract all types of personnel in the school. The introduction of high-quality talents can not only strengthen the reserve and use of talents, but also optimize the level and structure of the staff, thus improving the overall level of the logistics staff.

\section{SEVERAL PROBLEMS THAT SHOULD BE NOTICED IN THE PROCESS OF FIXING WORK POSTS AND DEFINING PERSONNEL} QUOTA

The first step the implementation of fixing work posts and defining personnel quota for logistics in colleges is based on the development strategy or business goals of the logistics itself. What kind of goals the university logistics needs to accomplish in a specific period is the center of all logistics work [4]. In order to ensure the smooth implementation of fixing work posts and defining personnel quota, and ultimately to achieve the development goals of the logistics group within a certain period of time, the following principles must be adhered to in the specific implementation:

\section{A. The Principle of Respecting Tradition and Taking into Full Consideration offfuture}

Taking all things into consideration, both the current situation and the future development of logistics are taken into account, and the actual needs of the various departments must be combined with the implementation of fixing work posts and defining personnel quota to firmly prevent the overprovisioned positions, redundant positions, and falsely-set positions. Specifically, on the existing basis there should be no considerable sea changes in post setting, the increase or decrease of the staffing and etc., so as to maintain the stability of logistics human resources management. However, at the same time, it is necessary to clarify the Group' s strategic objectives and major tasks for development. Adhere to the principle that "business determines jobs, job determines employees", and persist in high standards and high demands, make good use of people, choose the right people, cultivate people, and do a good job in echelon construction of logistic talents. To establish a team of employees who need to adapt to the long-term development of logistics.

\section{B. The Principle of Combining Centralized Management with the Decentralization of Authority}

The group makes plan as a whole, and the department makes decision independently. The logistics will guide all departments through the formulation of the unified arrangement method of fixing work posts and defining personnel quota. Under the premise of observing the general principles, all units shall formulate corresponding specific implementation plans according to the actual conditions of their departments, and submit them for logistic approval before implementation. In particular, the modes, methods and principles for the implementation of fixing work posts and defining personnel quota of the upper and middle management of logistics are formulated and implemented by the group. For front-line employees, they can delegate authority to all units for specific implementation. After all, the management and assessment of the first-line employees will be operated by each unit. Therefore, after the group has reviewed and approved the implementation plan of each unit, as long as it does not violate the laws and regulations or the rules of employ people of school, the group should not intervene too 
much in the implementation process. This will not only reduce the burden on the group, but also make it more practical and efficient for the implementation of fixing work posts and defining personnel quota.

\section{The Principle of Diversification of Employment Methods and the Principle of Reducing Staff and Increasing Efficiency}

Diversification of employment can maximize the use of limited logistics resources. Through the implementation of fixing work posts and defining personnel quota, combining the current management, technical level, and employment conditions, with reference to industry standards and the practice of other colleges, it can use various employment methods such as hiring outworkers, interns, seasonal workers and hourly workers and rehiring someone after retirement in different positions to make full use of the existing manpower and material resources. The purpose of fixing work posts and defining personnel quota is to tap the potentialities and increase the profit, while diversified employment methods can alleviate the waste of human and material resources caused by

"short-term work, long-term employment" , and can quickly and effectively solve temporary problems without adding new burdens to the group. This will make the group more flexible in employing people with the administration streamlined, redundant employees reduced and work efficiency improved.

\section{The Principle of Paying Equal Attention to the Minimum Number of Positions and Humanistic Care}

The post should be set up to ensure that the post's workload is full enough. Neither the arduous task causes the overdraft of the manpower of the post, nor can it be idle and the employee has nothing to do. Therefore, a post can be set up particularly for dealing with professional and complicated affairs, and for the more connected and relevant, easier work can be combined to set up posts, so that the transaction cost can be reduced, the coordination ability can be enhanced, and the minimum number of posts can meet the needs of the group work. Of course, the implementation of fixing work posts and defining personnel quota is not designed to lay off employees. But mainly adopt the method that all employees compete for a job to enable the group use the capable ones, replace the average ones and relief the incapable ones. It can also create a competitive atmosphere and stimulate employees' potential. Therefore, in the process of fixing work posts and defining personnel quota, it is not only the rigid implementation rules, but also the humanistic care and the maintenance of the legitimate rights and interests of employees. According to the Article6 of the General Provisions of the Labor Contract Law of the People's Republic of China, "The labor union shall assist and direct the employees when they conclude with the employers and fulfill labor contracts and establish a collective negotiation mechanism with the employers so as to maintain the lawful rights and interests of the employees." [5]. The labor union should help temporary employees in their ideological and practical actions, improving their political treatment, income, treatment and welfare benefits, and enhancing their sense of belonging.

\section{REFERENCES}

[1] WangYong, WangYan. Discussion on the role of college logistics grass-roots cadres in building first-class universities. [J]. Tsinghua Journal of Education, 2006, (S1):106-108.

[2] Qu Xianghua, Cai Chuyuan, Jiang Qiong. It is necessary to optimize the management of logistics team in colleges and universities [J]. Chinese Higher Education, 2016, (17):48-50.

[3] Ji Yongwei, Zhang Caiyan. The analysis and countermeasure of the present situation of the impermanent staff working in university logistics. [J]. Journal of Zhejiang Shuren University (Natural Science), 2012, (02):69-74.

[4] WangZirong Encouragement System for the Off-staff Workersin College Logistics [J] Sichuan University of Arts and Science Journal 2017, 27(01):61-64. [2017-09-03].

[5] Gu Zhengjun Research on Human Resources Management in the Socialization Reform of University's Logistics [D] Nanjing Agricultural University, 2018

[6] Standing Committee of the National People's Congress. Labor Contract Law of the People's Republic of China [M] China Legal Publishing House, 2009 